\title{
A comparative study of subcuticular and interrupted stitches for episiotomy
}

\author{
Pooja Thukral, Shweta Mendiratta*, Gunjan Bhola
}

Department of Obstetrics and Gynecology, Asian Institute of Medical Sciences, Faridabad, Haryana, India

Received: 11 October 2018

Accepted: 27 October 2018

\section{*Correspondence:}

Dr. Shweta Mendiratta,

E-mail: shwetsmendiratta@gmail.com

Copyright: (C) the author(s), publisher and licensee Medip Academy. This is an open-access article distributed under the terms of the Creative Commons Attribution Non-Commercial License, which permits unrestricted non-commercial use, distribution, and reproduction in any medium, provided the original work is properly cited.

\begin{abstract}
Background: Perineal pain is the most common complaint after episiotomy. For more than 70 years researchers have been suggesting that 'continuous non-locking suture techniques' for repair of the vagina, perineal muscle and skin are associated with less perineal pain than 'traditional interrupted methods'. The objective of the present study was to compare the two techniques of episiotomy closure in patients after vaginal delivery with mediolateral episiotomy. Methods: This study was conducted in the Department of Obstetrics and Gynecology, Asian Institute of medical sciences, Faridabad. The duration of study was from July 2017 to August 2017. Total 50 patients were selected and randomly divided in two groups. This was a prospective comparative study between continuous and interrupted suturing used for episiotomy repair.

Results: Continuous suturing technique requires lesser number of suture material, needs lesser time and is associated with lesser pain experience.

Conclusions: It was concluded from the present study that continuous suturing technique is more economical and causes lesser morbidity than the interrupted suturing technique.
\end{abstract}

Keywords: Episiotomy, Perineal, Suturing

\section{INTRODUCTION}

Perineal pain is the most common complaint after episiotomy. It imposes extra pressure on mothers who try to adapt to new conditions. Pain and sexual discomfort are most common problems experienced by females after episiotomy repair. ${ }^{1}$ The maternal morbidity is affected by the extent of trauma, surgical skills, type of material used and the suturing technique. ${ }^{2}$ The suturing technique of perineal trauma following child birth has a significant short- and long-term effect on the extent and degree of morbidity experienced by women.

Traditionally continuous locking stitches are used over vagina followed by interrupted stitches over the perineal muscles and skin. There have been studies to show that subcuticular sutures are far better than routine interrupted sutures. But till now subcuticular sutures are not routinely used. Millions of women worldwide undergo perineal suturing after childbirth and the type of repair may have an impact on pain and healing. For more than 70 years, researches have been suggesting that 'continuous nonlocking suture techniques' for repair of the vagina, perineal muscle and skin are associated with less perineal pain than 'traditional interrupted methods'. 3

Therefore, in this study authors compared two episiotomy repair methods and tried to present the best method with least complication rate.

The better technique would require lesser time, cause lesser pain and use lesser amount of suture material. So, 
the same parameters have been used in the present study to compare the two techniques of episiotomy closure. Using the better technique, that is the continuous subcuticular suturing as shown in this study would have long term economical benefits by reducing the maternal morbidity in terms of pain and secondly by lesser amount of suture material.

\section{METHODS}

This study was conducted in the Department of Obstetrics and Gynecology, Asian Institute of medical sciences, Faridabad. The duration of study was from July 2017 to August 2017. Total 50 patients were selected and randomly divided in two groups. Patients in group A (25) were given subcuticular stitches and patients in group B (25) were given interrupted stitches. Rapid vicryl number no 1 was used in both groups.

\section{Inclusion criteria}

- Singleton term pregnancy with vertex presentation

- Vaginal birth with or without instrumentation.

\section{Exclusion criteria}

- Preterm pregnancy

- Malpresentation

- Multiple gestation

- Associated vaginal or perineal tears

- Co morbid conditions like severe anemia, vulval edema, liver and kidney disease Previous history of episiotomy gaping or perineal infection.

The present study was a prospective comparative study between continuous and interrupted suturing used for episiotomy repair. Patient selection and type of suturing method used was done randomly. Suture material used in both the groups were same i.e. rapidly absorbable polygalactin suture material. Group A was repaired with continuous non-locking sutures involving the vaginal mucosa, perineal muscle and subcutaneous tissue of skin.
Group B had continuous sutures in vaginal mucosa, interrupted sutures in perineal muscle and interrupted transcutaneous stitches for skin. This study was double blinded. One group of researchers sutured episiotomy and those who collected the data were unaware of the technique used for that particular patient. Patients were also not aware of technique used. Immediately after repair of perineum, the number of sutures was counted, and time taken for repair was recorded. Cases were examined on day 2, 7 and 42 following repairs regarding pain perception while lying, sitting, moving and defecation.

\section{Statistical analysis}

Statistical analysis was done using SPSS 17 software. The student $\mathrm{t}$ test was used for continuous variables. Here $\mathrm{p}<0.05$ was considered statistically significant.

\section{RESULTS}

A total of 50 patients were recruited for the study that underwent delivery at Asian Institute of medical sciences from July 2017 to Aug 2017. They were randomly allocated to 25 in each group of subcuticular (Group A) and interrupted sutures (Group B) for perineal repair. Both the groups were comparable in their demographic characteristics viz age, gravidity and parity (Table 1 and 2).

Table 1: Comparison of age groups in both the study arms.

\begin{tabular}{|c|c|c|c|}
\hline & $\mathbf{A}$ & B & P value \\
\hline Age & & & \multirow{6}{*}{0.555} \\
\hline Sample size & 25 & 25 & \\
\hline Mean \pm SD & $28.92 \pm 3.53$ & $29.56 \pm 4.05$ & \\
\hline Median & 29 & 29 & \\
\hline Min-Max & $22-36$ & $22-37$ & \\
\hline $\begin{array}{l}\text { Inter quartile } \\
\text { range }\end{array}$ & $26.750-31.250$ & $27-32.250$ & \\
\hline
\end{tabular}

Table 2: Demographic characteristics-gravidity and parity.

\begin{tabular}{|c|c|c|c|c|}
\hline & \multicolumn{2}{|l|}{ Group } & Total & \multirow[t]{2}{*}{ P-value } \\
\hline & A & B & & \\
\hline \multicolumn{5}{|l|}{ Gravidity } \\
\hline Gravida 1 & $13(52.00 \%)$ & $10(40.00 \%)$ & $23(46.00 \%)$ & \multirow{5}{*}{0.534} \\
\hline Gravida 2 & $8(32.00 \%)$ & $12(48.00 \%)$ & $20(40.00 \%)$ & \\
\hline Gravida 3 & $3(12.00 \%)$ & $3(12.00 \%)$ & $6(12.00 \%)$ & \\
\hline Gravida 4 & $1(4.00 \%)$ & $0(0.00 \%)$ & $1(2.00 \%)$ & \\
\hline Total & $25(100.00 \%)$ & $25(100.00 \%)$ & $50(100.00 \%)$ & \\
\hline \multicolumn{5}{|l|}{ Parity } \\
\hline Parity 0 & $13(52.00 \%)$ & $10(40.00 \%)$ & $23(46.00 \%)$ & \multirow{4}{*}{0.664} \\
\hline Parity 1 & $9(36.00 \%)$ & $12(48.00 \%)$ & $21(42.00 \%)$ & \\
\hline Parity 2 & $3(12.00 \%)$ & $3(12.00 \%)$ & $6(12.00 \%)$ & \\
\hline Total & $25(100.00 \%)$ & $25(100.00 \%)$ & $50(100.00 \%)$ & \\
\hline
\end{tabular}


As shown in Table 1 age of patients was comparable in both the groups with the median age being 29 in both the groups. Most of the patients in Group A were primigravida whereas in group B, $40 \%$ were primigravida and $48 \%$ had one previous pregnancy. Most of the patients in Group A had no previous delivery (52\%) whereas in group B $48 \%$ had 1 previous delivery. However, this was not statistically significant (Table 2).

\section{Time taken for suturing}

The time taken to suture in the continuous group was less than 5 min and was more than 5 minutes in the group in which interrupted sutures were used (Table 3 ) with the median time being 8 minutes with interrupted suturing technique and 6 minutes with continuous suturing technique.
Table 3: Time taken for suturing.

\begin{tabular}{|c|c|c|c|}
\hline \multicolumn{4}{|c|}{ Time taken (minutes) } \\
\hline Sample size & $\begin{array}{l}25 \\
\text { (interrupted) }\end{array}$ & $\begin{array}{l}25 \\
\text { (continuous) }\end{array}$ & \multirow{5}{*}{$<0.0001$} \\
\hline Mean \pm SD & $7.7 \pm 1.24$ & $5.78 \pm 0.67$ & \\
\hline Median & 8 & 6 & \\
\hline Min-Max & $6-10$ & $5-7$ & \\
\hline $\begin{array}{l}\text { Inter quartile } \\
\text { range }\end{array}$ & $6.875-8.625$ & $5-6.125$ & \\
\hline
\end{tabular}

Less suture material was required for the repair of perineum in the continuous suturing than the interrupted technique (Table 4). In group A i.e. interrupted suturing technique group, 15 patients required 2 suture materials whereas none required 2 suture materials in group B i.e. continuous suturing group.

Table 4: Number of sutures used.

\begin{tabular}{|c|c|c|c|c|c|c|}
\hline & Group & & Total & P value & $\mathbf{R} \mathbf{R}$ & 1 suture:2 suture \\
\hline No. of sutures & $\mathbf{A}$ & B & & \multirow{4}{*}{$<0.0001$} & \multirow{4}{*}{0.4118} & \multirow{4}{*}{0.2573 to 0.6589} \\
\hline Suture 1 & $10(40.00 \%)$ & $25(100.00 \%)$ & $35(70.00 \%)$ & & & \\
\hline Suture 2 & $15(60.00 \%)$ & $0(0.00 \%)$ & $15(30.00 \%)$ & & & \\
\hline Total & $25(100.00 \%)$ & $25(100.00 \%)$ & $50(100.00 \%)$ & & & \\
\hline
\end{tabular}

Table 5: Pain score on day 2.

\begin{tabular}{|c|c|c|c|c|c|c|}
\hline \multicolumn{7}{|c|}{ Group } \\
\hline $\begin{array}{l}\text { Day } 2 \\
\text { (Pain score) }\end{array}$ & $\mathbf{A}$ & B & Total & $P$ value & $\mathbf{R R}$ & $\begin{array}{l}\text { Slight pain: moderate+severe } \\
(95 \% \text { CI })\end{array}$ \\
\hline Slight & $13(52.00 \%)$ & $22(88.00 \%)$ & $35(70.00 \%)$ & \multirow{4}{*}{0.019} & \multirow{4}{*}{0.5909} & \multirow{4}{*}{0.3947 to 0.8846} \\
\hline Moderate & $11(44.00 \%)$ & $3(12.00 \%)$ & $14(28.00 \%)$ & & & \\
\hline Severe & $1(4.00 \%)$ & $0(0.00 \%)$ & $1(2.00 \%)$ & & & \\
\hline Total & $25(100.00 \%)$ & $25(100.00 \%)$ & $50(100.00 \%)$ & & & \\
\hline
\end{tabular}

Table 6: Pain score on day 7.

\begin{tabular}{|c|c|c|c|c|c|c|}
\hline & Group & & & & & \\
\hline $\begin{array}{l}\text { Day } 7 \\
\text { (Pain score) }\end{array}$ & $\mathbf{A}$ & B & Total & $P$ value & $\mathbf{R R}$ & $\begin{array}{l}\text { Slight pain: moderate+severe } \\
(95 \% \text { CI })\end{array}$ \\
\hline Slight & $11(44.00 \%)$ & $23(44.0 \%)$ & $44(44.00 \%)$ & \multirow{4}{*}{0.001} & \multirow{4}{*}{0.4783} & \multirow{4}{*}{0.3947 to 0.8846} \\
\hline Moderate & $11(44.00 \%)$ & $2(8.00 \%)$ & $13(26.00 \%)$ & & & \\
\hline Severe & $3(12.00 \%)$ & $0(0.00 \%)$ & $1(6.00 \%)$ & & & \\
\hline Total & $25(100 \%)$ & $25(100 \%)$ & $50(100 \%)$ & & & \\
\hline
\end{tabular}

Pain comparison on the second and seventh postpartum days revealed lesser pain experience in the continuous group when compared with the interrupted technique group (Table 5 and 6).

Most of patients (22) in Group B had slight pain whereas in group A, 11 patients had moderate pain and 1 patient had severe pain on day 2 . No patient had severe pain on day 2 with continuous suturing i.e. Group B (Table 5).
Similarly, on day 7, most patients (23) of group B had only slight pain whereas in group B 11 patients had slight pain, 11 had moderate pain and 3 had severe pain. No patient in group B had severe pain (Table 6).

\section{DISCUSSION}

In this study the demographic characteristics were comparable in both the groups to avoid the effect of age 
and parity on the incidence of pain. A trial comparing the continuous and interrupted technique of episiotomy repair using two suture materials (quick and standard absorption, conducted by Kettle at al showed that the group with continuous suturing technique experienced lesser pain., ${ }^{4,5}$

In this study the pain experience was lesser with the continuous suturing technique group on postpartum day 2 and day 7. Almeida et al compared similarly and found more pain in the interrupted suture technique group. ${ }^{6}$ Present study had results similar to the study conducted by Dash $\mathrm{S}$ et al showed that continuous suturing technique for perineal closure is associated with less short term pain and requires lesser number of sutures and less time. ${ }^{7}$ Present study had similar results with lesser time taken i.e. less than 5 minutes with continuous suturing technique whereas interrupted suturing took more than 5 minutes on an average (Table 3). Similar to above studies, lesser suture was used with continuous suturing technique (Table 4). Kokanali D et al also showed less short term pain, lesser time and also need of less suture material in the group with continuous suturing technique. ${ }^{8}$ Present study had similar results and showed lesser pain observed with continuous suturing technique on Day 2 and Day 7 as shown in Tables 5 and 6. The study conducted by Morano et al reported that significantly fewer women reported pain at 10 days with the continuous knotless technique. ${ }^{9}$ Study by Valenzuela et al, had results similar to us and showed that episiotomy and perineal tear repairs with continuous suturing used lesser time and suture material and there was no increase in complication rates when compared with interrupted technique of suturing. ${ }^{10}$

\section{CONCLUSION}

It was concluded from the present study that continuous suturing technique is more economical than the interrupted suturing technique as it requires lesser number of suture material, needs lesser time and is associated with lesser pain experience. Most of the studies in the past showed similar results as shown above. Using the continuous method for episiotomy closure would be more economical as it reduces maternal morbidity in terms of pain and requires lesser time and suture material.

\section{ACKNOWLEDGMENTS}

Authors would like to thank colleagues especially in the Department of Obstetrics and Gynecology, Asian Institute of Medical Sciences, Faridabad, Haryana, India who helped while conducting the research.
Funding: No funding sources

Conflict of interest: None declared

Ethical approval: The study was approved by the Institutional Ethics Committee

\section{REFERENCES}

1. Fernando R, Sultan AH, Kettle C, Thakar R, Radley S. Methods of repair for obstetric anal sphincter injury. Cochrane Database Syst Rev. 2006;19(3):CD002866.

2. Carroli G, Migini L. Episiotomy for vaginal birth. Cochrane Database Syst Rev. 2009;CD000081.

3. Weber AM, Meyn L. Episiotomy use in the United States, 179-1997. Obstet Gynaecol. 2002;100(6):1177-82.

4. Kettle C, Dowswell T, Ismail KM. Absorbable suture materials for primary repair of episiotomy and second degree tears. Cochrane Database Syst Rev. 2010;16(6):CD000006.

5. Kettle C, Dowswell T, Ismail KM. Continuous and interrupted suturing techniques for repair of episiotomy or second- degree tears. Cochrane Database Syst Rev. John Wiley and Sons; 2012:14.

6. Almeida SF, Riesco ML. Randomized controlled clinical trial on two perineal trauma suture techniques in normal delivery. Rev Lat Am Enfermagem. 2008;16(2):272-9.

7. Dash S, Nanda SS, Behera A, Mishra B. Continuous versus interrupted sutures for episiotomy wound and perineal tear repair. Scholars J Applied Med Sci. 2013;1(6):710-3.

8. Kokanali D, Ugur M, Kuntay Kokanali M, Karayalcin R, Tonguc E. Continuous versus interrupted episiotomy repair with monofilament or multifilament absorbed suture materials: a randomized controlled trial. Arch Gynecol Obstet. 2011;284(2):275-80.

9. Morano S, Mistrangelo E, Pastorino D, Lijoi D, Costantini S, Ragini N. A randomized comparison of suturing techniques for episiotomy and laceration repair after spontaneous vaginal birth. J Minim Invasive Gynecol. 2006;13(5):457-62.

10. Valenzuela P, Saiz Puente MS, Valero JL, Azorin R, Ortega R, Guijarro R. Continuous versus interrupted sutures for repair of episiotomy or second degree perineal tears: a randomised controlled trial. BJOG. 2009;116(3):436-41.

Cite this article as: Thukral $\mathrm{P}$, Mendiratta $\mathrm{S}$, Bhola G. A comparative study of subcuticular and interrupted stitches for episiotomy. Int J Reprod Contracept Obstet Gynecol 2018;7:5107-10. 